ARTICLE

Received 30 Apr 2014 | Accepted 14 Nov 2014 | Published 16 Jan 2015

DOI: $10.1038 /$ ncomms6851 OPEN

\title{
Porous coordination polymers with ubiquitous and biocompatible metals and a neutral bridging ligand
}

Shin-ichiro Noro ${ }^{1,2,3,4}$, Junya Mizutani ${ }^{2}$, Yuh Hijikata ${ }^{5}$, Ryotaro Matsuda ${ }^{3,6}$, Hiroshi Sato ${ }^{6}$, Susumu Kitagawa ${ }^{6}$, Kunihisa Sugimoto ${ }^{7}$, Yasutaka Inubushi ${ }^{8, \dagger}$, Kazuya Kubo ${ }^{1,2}$ \& Takayoshi Nakamura ${ }^{1,2}$

The design of inexpensive and less toxic porous coordination polymers (PCPs) that show selective adsorption or high adsorption capacity is a critical issue in research on applicable porous materials. Although use of Group II magnesium(II) and calcium(II) ions as building blocks could provide cheaper materials and lead to enhanced biocompatibility, examples of magnesium(II) and calcium(II) PCPs are extremely limited compared with commonly used transition metal ones, because neutral bridging ligands have not been available for magnesium(II) and calcium(II) ions. Here we report a rationally designed neutral and charge-polarized bridging ligand as a new partner for magnesium(II) and calcium(II) ions. The three-dimensional magnesium(II) and calcium(II) PCPs synthesized using such a neutral ligand are stable and show selective adsorption and separation of carbon dioxide over methane at ambient temperature. This synthetic approach allows the structural diversification of Group II magnesium(II) and calcium(II) PCPs.

\footnotetext{
${ }^{1}$ Research Institute for Electronic Science, Hokkaido University, Sapporo 001-0020, Japan. ${ }^{2}$ Graduate School of Environmental Earth Science, Hokkaido University, Sapporo 060-0810, Japan. ${ }^{3}$ PRESTO, Japan Science and Technology Agency (JST), 4-1-8 Honcho, Kawaguchi 332-0012, Japan. ${ }^{4}$ Creative Research Institute (CRIS), Hokkaido University, Sapporo 001-0021, Japan. ${ }^{5}$ Institute of Transformative Bio-Molecules (WPI-ITbM), Nagoya University, Chikusa-ku, Nagoya 464-8602, Japan. ${ }^{6}$ Institute for Integrated Cell-Material Science (WPI-iCeMS), Kyoto University, Kyoto 615-8510, Japan. ${ }^{7}$ Research and Utilization Division, Japan Synchrotron Radiation Research Institute, Hyogo 679-5198, Japan. ${ }^{8}$ Synthesis Research Laboratory, Kurashiki Research Center, Kuraray Co. Ltd., Sakazu, Kurashiki, Okayama 710-0801, Japan. †Present address: EVAL Research and Development Department, EVAL Division, Vinyl Acetate Company, Kuraray Co. Ltd., 7471, Tamashimaotoshima, Kurashiki, Okayama 713-8550, Japan. Correspondence and requests for materials should be addressed to S.-i.N. (email: noro@es.hokudai.ac.jp) or to T.N. (email: tnaka@es.hokudai.ac.jp).
} 
$\mathrm{P}$ orous coordination polymers (PCPs) or metal-organic frameworks (MOFs) constructed from metal ions and organic bridging ligands have attracted much attention as intriguing porous materials because of their high structural regularity and diversity, easy modification of frameworks, high porosity and structural flexibility ${ }^{1-13}$. One of the main trends in work on these materials is the development and improvement of their porous functions, such as storage ${ }^{14,15}$, separation ${ }^{16-18}$ and catalysis $^{19-21}$. Towards industrial and biological applications, however, we must consider costs and safety of PCPs in addition to their porous performances. Generally, first-transition-row divalent metal ions such as $\mathrm{Co}(\mathrm{II}), \mathrm{Ni}(\mathrm{II}), \mathrm{Cu}(\mathrm{II})$ and $\mathrm{Zn}(\mathrm{II})$ have been utilized as metal sources of PCPs. On the other hand, Group II metal ions, $\mathrm{Mg}(\mathrm{II})$ and $\mathrm{Ca}(\mathrm{II})$, belonging to the light metal ions are in abundant supply on the Earth and biofriendly 22,23 . If Group II $\mathrm{Mg}$ (II) or $\mathrm{Ca}(\mathrm{II})$ ions are embedded in PCP frameworks instead of first-transition-row metal ions, the resulting PCPs could become cheaper and have higher biocompatibility.

Nevertheless, the examples of $\mathrm{Mg}$ (II) and $\mathrm{Ca}(\mathrm{II})$ PCPs are extremely limited to date compared with transition metal $\mathrm{PCPs}^{23-29}$, because neutral bridging ligands have not been available for the construction of Group II $\mathrm{Mg}$ (II) and $\mathrm{Ca}$ (II) PCPs. Transition metal ions are classed as medium acids according to the hard and soft acids and bases theory. According to this theory, a variety of organic bridging ligands containing anionic carboxylate or imidazolate, and neutral pyridine or imidazole units, tend to be coordinated to them, which makes the PCP frameworks diversified. Furthermore, the combination of anionic and neutral organic bridging ligands is much more effective in diversifying transition metal PCP frameworks. By contrast, $\mathrm{Mg}(\mathrm{II})$ and $\mathrm{Ca}(\mathrm{II})$ ions are hard acids and, therefore, organic ligands with hard basicity, that is, anionic multicarboxylates have been their sole partners. This is one of the reasons why $\mathrm{Mg}$ (II) and $\mathrm{Ca}(\mathrm{II})$ PCPs have not been thoroughly investigated.

To overcome this problem, we introduce a new partner, $4,4^{\prime}$ bipyridine- $N, N^{\prime}$-dioxide (bpdo), which is a neutral and chargepolarized bridging ligand with pyridine- $N$-oxide (pyo) moieties, to Group II $\mathrm{Mg}$ (II) and $\mathrm{Ca}$ (II) ions. Although the structure of the neutral bpdo ligand is similar to that of the neutral ligand $4,4^{\prime}$ bipyridine $\left(4,4^{\prime}\right.$-bpy), we expect that it can coordinate to hard Group II $\mathrm{Mg}(\mathrm{II})$ and $\mathrm{Ca}(\mathrm{II})$ ions through negatively charged oxygen atoms with hard basicity, despite a totally neutral ligand (Fig. 1a). In this study, using the neutral and charge-polarized bridging ligand bpdo, we demonstrate rational design and syntheses of $\mathrm{Mg}(\mathrm{II})$ and $\mathrm{Ca}(\mathrm{II})$ PCPs connected by neutral organic ligands. The resulting $\mathrm{Mg}(\mathrm{II})$ and $\mathrm{Ca}(\mathrm{II}) \mathrm{PCPs}$, which are the uncommon examples including neutral bridging ligands, are stable after the removal of guest molecules and show selective adsorption and separation of $\mathrm{CO}_{2}$ over $\mathrm{CH}_{4}$ at ambient temperature. Our finding contributes to the structural diversification of PCP frameworks with ubiquitous and biocompatible metals.

\section{Results}

Charge distribution. First, we evaluated the hard basicity of the bpdo ligand. Generally, the bond between a hard acid and a hard base is dominated by an ionic interaction. The bpdo ligand has two coordinated oxygen atoms, which are better coordination sites for hard acids than nitrogen atoms because of their larger negative charge. We calculated the charge distribution of a bpdo ligand with other typical and similar organic ligands, pyo, 4,4'-bpy, benzoate $\left(\mathrm{bza}^{-}\right)$and 4,4'-biphenyldicarboxylate $\left(4,4^{\prime}-\right.$ bpdc $\left.^{2-}\right)$ to compare the strengths of ionic interactions. It is well known that pyo and their derivatives show a variety of resonance structures. We investigated which resonance structures mainly contribute to the actual structure. Figure $1 \mathrm{~b}$ shows five resonance structures of a pyo derivative and Fig. 1c shows electron occupation numbers for each bond and natural bond orbital (NBO) charges for each atom in bpdo, which were obtained by the density functional theory. The negative charges are localized on the oxygen atoms, and little $\pi$-bond character is observed between the nitrogen and oxygen atoms, supporting the main contribution of the resonance structures (I), (II) and (III). Figure 1d and Supplementary Fig. 1 show NBO charges. The oxygen atoms of the neutral bpdo and pyo ligands have negative charges of $-0.543 \mathrm{e}$ and $-0.568 \mathrm{e}$, respectively, which are smaller than those for anionic carboxylate-type bza ${ }^{-}$and $4,4^{\prime}$ bpdc ${ }^{2}-$ ligands ( -0.795 e and -0.805 e, respectively) but larger than the negative charges of the nitrogen atoms of the neutral $4,4^{\prime}$-bpy ligand ( $-0.446 \mathrm{e}$ ). All calculation results conclude that the neutral ligands with pyo moieties should act as stronger hard bases than 4,4'-bpy and be good partners for hard Group II $\mathrm{Mg}(\mathrm{II})$ and $\mathrm{Ca}(\mathrm{II})$ ions.

Structural characterization. To experimentally prove this new strategy, we next attempted to synthesize Group II $\mathrm{Mg}(\mathrm{II})$ and $\mathrm{Ca}(\mathrm{II})$ coordination polymers using the neutral bpdo ligand. The reaction of $\mathrm{Mg}(\mathrm{AcO})_{2} \bullet 4 \mathrm{H}_{2} \mathrm{O}$ with bpdo yielded the two-dimensional coordination polymer $\left[\mathrm{Mg}_{2}(\mathrm{AcO})_{4}(\mathrm{bpdo})\right]_{n}$ (1). Further, the reaction of $\mathrm{MgCl}_{2} \bullet 6 \mathrm{H}_{2} \mathrm{O}$ or $\mathrm{Ca}\left(\mathrm{NO}_{3}\right)_{2} \bullet 4 \mathrm{H}_{2} \mathrm{O}$ with 1,4-benzenedicarboxylic acid $\left(1,4-\mathrm{H}_{2}\right.$ bdc) and bpdo in $\mathrm{N}, \mathrm{N}$-dimethylformamide (DMF) afforded the three-dimensional PCPs, $\left\{\left[\mathrm{Mg}_{2}(1,4-\mathrm{bdc})_{2}(\mathrm{bpdo})\right] \bullet 2 \mathrm{DMF}\right\}_{n} \quad(2 \supset 2 \mathrm{DMF})$ and $\{[\mathrm{Ca}(1,4-$ bdc)(bpdo) $] \bullet 0.5 \mathrm{DMF}\}_{n} \quad(3 \supset 0.5 \mathrm{DMF}) . \quad$ As expected, $\mathbf{1}$, $2 \supset 2 \mathrm{DMF}$ and $3 \supset 0.5 \mathrm{DMF}$ included the neutral bpdo ligands that bridge the metal centres. The crystal structures of $\mathbf{1}$, $2 \supset 2 \mathrm{DMF}$ and $3 \supset 0.5 \mathrm{DMF}$ were determined using single-crystal X-ray crystallography at $173 \mathrm{~K} .1$ has an octahedral $\mathrm{Mg}(\mathrm{II})$ environment with four $\mathrm{AcO}^{-}$oxygen atoms and two bpdo oxygen atoms. The $\mathrm{Mg}-\mathrm{O}\left(\mathrm{AcO}^{-}\right)$bond distances (2.017(6)2.085(6) $\AA$ ) are slightly shorter than the Mg-O(bpdo) bond distances $(2.154(4)$ and $2.161(4) \AA)$. The $\mathrm{Mg}(\mathrm{II})$ centres are bridged by two carboxylate parts and one pyo part to form one-dimensional $\mathrm{Mg}(\mathrm{II})$ chains with the corner-shared $\mathrm{MgO}_{6}$ octahedral units running along the $b$-axis. These one-dimensional chains are further linked by bpdo ligands, resulting in the two-dimensional coordination network (Fig. 2a).

In $2 \supset 2 \mathrm{DMF}$, the $\mathrm{Mg}$ (II) centre has an octahedral environment with four 1,4-bdc ${ }^{2}-$ oxygen atoms and two bpdo oxygen atoms (Fig. 2b). The corner-shared $\mathrm{MgO}_{6}$ octahedral units interconnected by both organic moieties form infinite chains (Supplementary Fig. 2). These chains are further bridged by both bpdo and 1,4-bdc ${ }^{2}$ ligands, affording a three-dimensional porous coordination framework with one-dimensional channels (Fig. $2 c$, channel size: $4.5 \times 4.1 \AA^{2}$ ) occupied by guest DMF molecules. The accessible volume of the fully desolvated 2 is ca $35.6 \%$, which was calculated using the PLATON programme (probe radius: $1.2 \AA)^{30}$.

In $3 \supset 0.5 \mathrm{DMF}$, the $\mathrm{Ca}(\mathrm{II})$ centre has an octahedral environment with four 1,4 -bdc ${ }^{2}-$ oxygen atoms and two bpdo oxygen atoms arranged in a cis conformation (Fig. 2d). The $\mathrm{CaO}_{6}$ octahedral units are interconnected by two carboxylate parts to form one-dimensional $\mathrm{Ca}(\mathrm{II})$ chains (Supplementary Fig. 3). These chains are bridged by $1,4-\mathrm{bdc}^{2}-$ ligands, affording twodimensional layers parallel to the $a c$ plane. These layers are further connected by bpdo ligands, forming a three-dimensional porous coordination framework with one-dimensional channels (Fig. $2 \mathrm{e}$, channel size: $3.4 \times 3.2 \AA^{2}$ ) that contain guest DMF 
a
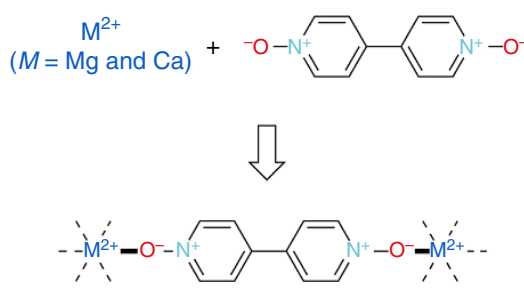

b

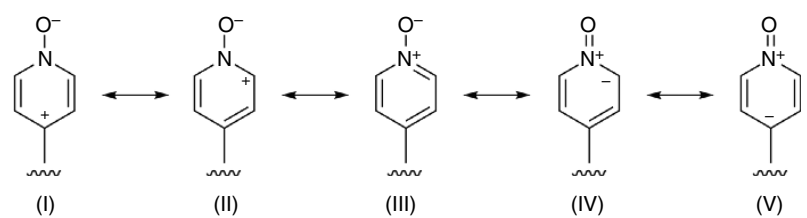

C

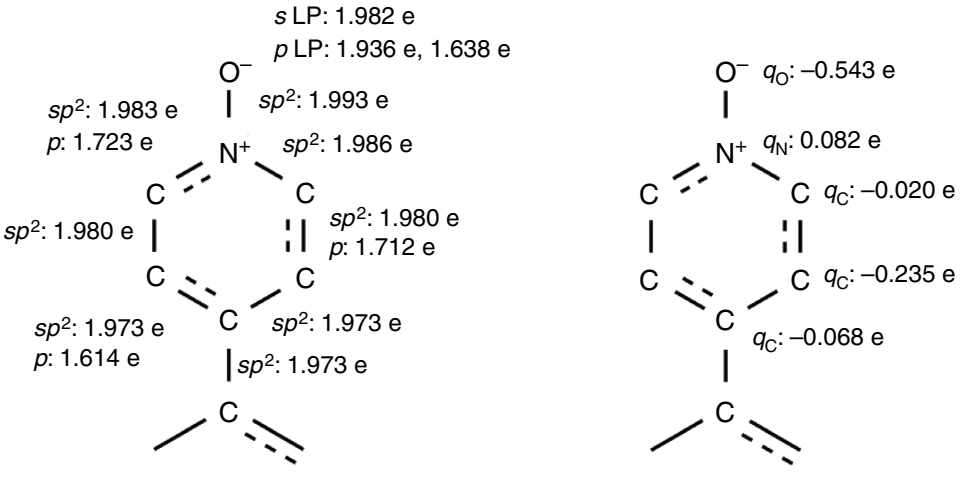

d
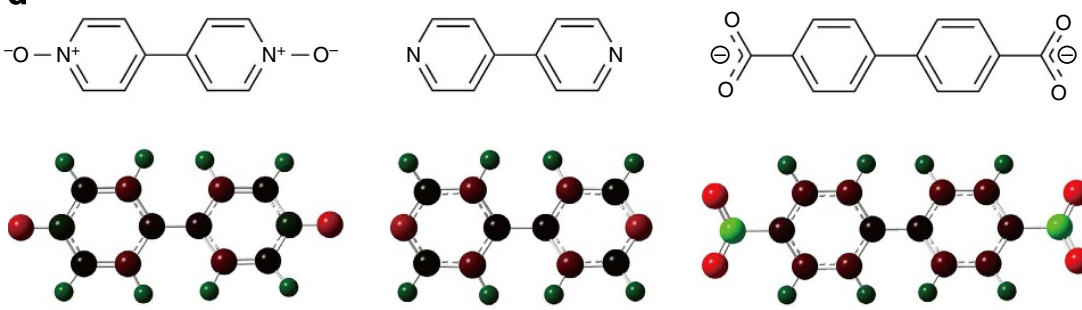

$\mathrm{N}: 0.082 \mathrm{e}$

$\mathrm{O}:-0.543 \mathrm{e}$

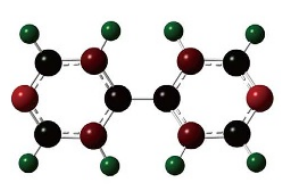

$\mathrm{N}:-0.446 \mathrm{e}$

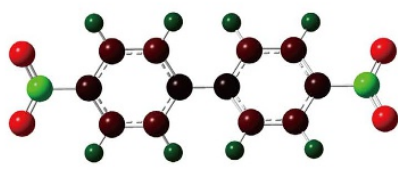

O: -0.805 e

Figure 1 | Designing organic ligands for magnesium(II) and calcium(II) porous coordination polymer. (a) New neutral partner, 4,4'-bipyridine- $N, N^{\prime}-$ dioxide (bpdo), for hard Group II $\mathrm{Mg}(\mathrm{II})$ and $\mathrm{Ca}(\mathrm{II})$ ions. (b) Five resonance structures in a pyridine- $\mathrm{N}$-oxide derivative. (c) Electron occupation numbers for each bond and natural bond orbital (NBO) charges for each atom in bpdo. (d) NBO charges for selected atoms in organic bpdo, 4,4'-bipyridine and 4,4'-biphenyldicarboxylate ligands.

molecules. From the calculation using the PLATON programme, the accessible volume of the fully desolvated 3 was found to be ca $21.1 \%$, smaller than that in $\mathbf{2}$ (ref. 30 ).

It was confirmed from theoretical and experimental results that the neutral organic bpdo ligand has hard basicity and is a good partner to hard Group II $\mathrm{Mg}$ (II) and $\mathrm{Ca}(\mathrm{II})$ ions. It should be noted that the NBO charge of oxygen atoms in the bpdo ligand $(-0.543 \mathrm{e})$ is considerably smaller than $-1 \mathrm{e}$, which is the maximum value when only the resonance structures of (I), (II) and (III) contribute to the electronic structure of bpdo. This means that the negative charge on the oxygen atoms of the bpdo ligand may further increase by ionic interactions with cationic Group II metal ions. To clarify this, infrared spectra were measured (Supplementary Figs 4 and 5); these showed that the $\mathrm{N}-\mathrm{O}$ stretching band of bpdo in $2 \supset 2 \mathrm{DMF}\left(1,225 \mathrm{~cm}^{-1}\right)$ shifts to a lower wavenumber than that of free bpdo ligand $\left(1,242 \mathrm{~cm}^{-1}\right)$, suggesting an enhanced single bond character and negative charge accumulation by coordination to $\mathrm{Mg}(\mathrm{II})$ ions. Furthermore, the NBO charge of the model structure of 2, $\left[\mathrm{Mg}_{4}(\mathrm{bza})_{4}(\mathrm{OH})_{4}(\mathrm{bpdo})\left(\mathrm{H}_{2} \mathrm{O}\right)_{8}\right]$ (Supplementary Fig. 6), was calculated. As shown in Supplementary Fig. 7, the coordinated bpdo ligand has oxygen atoms with an NBO charge of $-0.660 \mathrm{e}$, $21.5 \%$ higher than that of coordination-free bpdo, whereas the NBO charge of the oxygen atoms in the carboxylate ligand, bza $^{-}$, is only changed by -1.1 to $2.1 \%$ before and after the coordination, indicating that the hard basicity of the bpdo ligand indeed increases by coordination to cationic Group II $\mathrm{Mg}$ (II) ions. The $\mathrm{N}-\mathrm{O}$ bond of bpdo in the model structure increases in length by further negative charge accumulation on bpdo oxygen atoms (Supplementary Table 1). On the other hand, the 

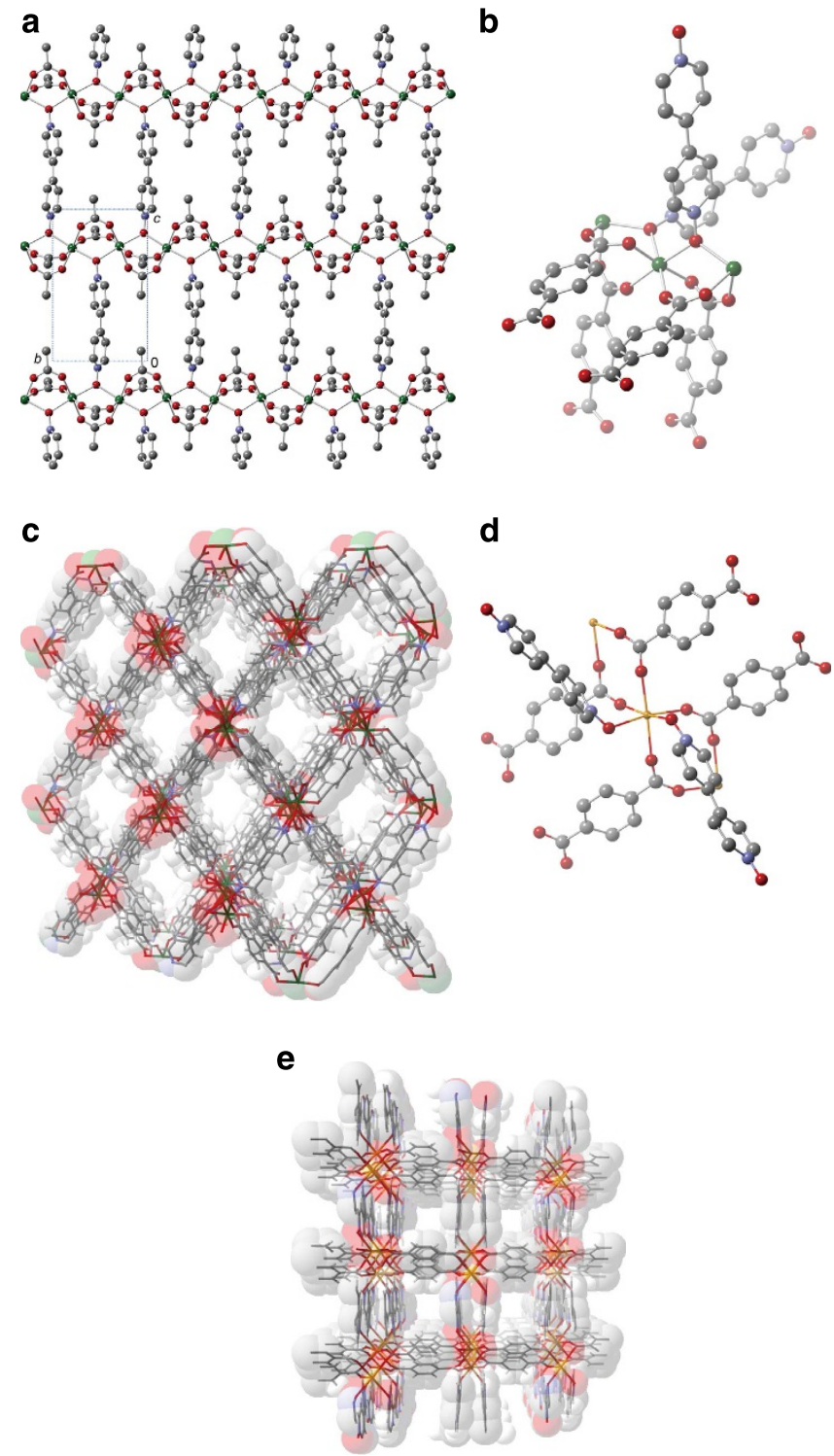

Figure 2 | Crystal structures. (a) Two-dimensional structure of 1. (b) Coordination environment around the $\mathrm{Mg}(\mathrm{II})$ centre in $\mathbf{2} \supset 2 \mathrm{DMF}$ $(\mathrm{DMF}=\mathrm{N}, \mathrm{N}$-dimethylformamide). (c) Porous structure in $\mathbf{2} \supset 2 \mathrm{DMF}$ (the guest DMF molecules are omitted). (d) Coordination environment around the $\mathrm{Ca}(\mathrm{II})$ centre in $\mathbf{3} \supset 0.5 \mathrm{DMF}$. (e) Porous structure in $\mathbf{3} \supset 0.5 \mathrm{DMF}$ (the guest DMF molecules are omitted). In $\mathbf{a}, \mathbf{b}$ and $\mathbf{d}$, the hydrogen atoms are omitted for clarity. Green represents magnesium; orange, calcium; red, oxygen; blue, nitrogen; grey, carbon and white, hydrogen.

corresponding $\mathrm{N}-\mathrm{O}$ stretching band position in $3 \supset 0.5 \mathrm{DMF}$ $\left(1,240 \mathrm{~cm}^{-1}\right)$ is almost the same as that of the free bpdo ligand, because a $\mathrm{Ca}(\mathrm{II})$ ion (effective ion radius: $1.00 \AA$ (ref. 31$)$ ) with lower charge density than a $\mathrm{Mg}(\mathrm{II})$ ion (effective ion radius: $0.720 \AA$ (ref. 31)) cannot induce further charge accumulation. These results indicate that $\mathbf{2}$ has more polar channels than $\mathbf{3}$, which affects the adsorption properties (vide infra).

Framework stability. To evaluate the framework stability, thermogravimetry-differential thermal analyses (TG-DTA) and powder X-ray diffraction (XRD) analyses of the desolvated 2 and 3 were performed. 2 was prepared by heating the EtOHexchanged sample at $373 \mathrm{~K}$ under vacuum, whereas 3 was obtained by the direct removal of DMF molecules from
$3 \supset 0.5 \mathrm{DMF}$ at $423 \mathrm{~K}$ under vacuum. TG-DTA analysis suggests that 2 and 3 are stable up to 573 and $473 \mathrm{~K}$, respectively (Supplementary Figs 8 and 9). The powder XRD patterns of the desolvated 2 and 3 (Supplementary Figs 10 and 11) show that the original frameworks are stable after the removal of guest molecules.

Porosity. We first measured the adsorption/desorption isotherms for $\mathrm{N}_{2}$ and $\mathrm{CO}_{2}$ at low temperature to investigate the fundamental porous properties. 1 shows no $\mathrm{CO}_{2}$ adsorption at $195 \mathrm{~K}$ (Supplementary Fig. 12), consistent with the fact that $\mathbf{1}$ has no permanent pores in the X-ray crystal structure. In the PCPs $\mathbf{2}$ and $3, \mathrm{CO}_{2}$ and $\mathrm{N}_{2}$ gases are adsorbed (Supplementary Figs 13 and 14). The $\mathrm{N}_{2}$ adsorption isotherms show type-I curves, indicative of permanent micropores. The Dubinin-Radushkevich plots give the micropore volumes of 0.19 and $0.085 \mathrm{~cm}^{3} \mathrm{~g}^{-1}$ for 2 and 3 , respectively. The $\mathrm{CO}_{2}$ adsorption/desorption isotherms in 3 also show type-I curves, whereas 2 shows a stepwise adsorption curve (Supplementary Fig. 14). Coincident infrared/adsorption measurements were performed for various $\mathrm{CO}_{2}$ pressures at $195 \mathrm{~K}$ to confirm the structural change. If the structural change occurs, an increase in infrared intensity at one point should be observed, with a decrease in infrared intensity at another point. In 3, the intensities of bands derived from the framework decrease with increasing adsorption (Supplementary Fig. 15), whereas the intensities of some bands increase at first and second adsorption events in 2 (Supplementary Fig. 16), suggesting the structural change of 2 associated with first and second $\mathrm{CO}_{2}$ adsorption. To investigate the structural changes of $\mathbf{2}$ in more detail, coincident XRD/adsorption measurements were conducted. Upon $\mathrm{CO}_{2}$ adsorption and desorption, pronounced changes in the XRD patterns were observed (Fig. 3 and Supplementary Fig. 17). The XRD pattern does not change dramatically in the initial $\mathrm{CO}_{2}$ adsorption (ads1 to ads5). After ads5, the XRD pattern changes and the structural change finishes at ads10. The structure again begins to change after ads12, and the peak positions in the XRD pattern at ads 19 where the second adsorption event is completed are similar to those of the desolvated 2. Further gradual $\mathrm{CO}_{2}$ adsorption after ads19 leads to the slight structural change. In the desorption process, the reverse change in the XRD patterns was observed. Because the crystal structure and the change in the XRD patterns upon $\mathrm{CO}_{2}$ adsorption and desorption in $\mathbf{2}$ are similar to those observed in $[\mathrm{Cr}(\mathrm{OH})(1,4-\mathrm{bdc})]_{n}(\mathrm{MIL}-53)^{32}$, we speculate that the pore contraction and re-expansion occur during $\mathrm{CO}_{2}$ adsorption/desorption in 2 (Supplementary Fig. 18).

Adsorption selectivity. The low-pressure $\mathrm{CO}_{2}, \mathrm{CH}_{4}, \mathrm{~N}_{2}, \mathrm{O}_{2}, \mathrm{Ar}$ and $\mathrm{H}_{2}$ adsorption isotherms for 2 at $298 \mathrm{~K}$ are compared in Fig. 4a. 2 adsorbs very small amounts of $\mathrm{N}_{2}, \mathrm{O}_{2}, \mathrm{Ar}$ and $\mathrm{H}_{2}$, and a small amount of $\mathrm{CH}_{4}$ at $298 \mathrm{~K}$. On the other hand, the uptake of $\mathrm{CO}_{2}$ at $97 \mathrm{kPa}$ is $\sim 12$ times higher than the uptake of $\mathrm{N}_{2}$. The effective interaction with polar $\mathrm{CO}_{2}$ gas causes a high selectivity for the adsorption of $\mathrm{CO}_{2}$ over other gases, which is a prerequisite for the application of a separation material. The adsorption of gas mixtures in porous materials can be reliably estimated from the ideal adsorbed solution theory (IAST), which is a precise method used to describe gas-mixture adsorption in representative zeolites and PCPs from the experimental single-component gas adsorption isotherms ${ }^{33}$. The predicted adsorption selectivities for $\mathrm{CO}_{2} /$ $\mathrm{CH}_{4}$ and $\mathrm{CO}_{2} / \mathrm{N}_{2}$ for a bulk gas composition of $\mathrm{CO}_{2}: \mathrm{CH}_{4}=40: 60$ (typical composition of biogas) and $\mathrm{CO}_{2}: \mathrm{N}_{2}=10: 90$ (typical composition of flue gas) are 21-16 and 87-67, respectively (Fig. 4b), high enough $(>8)$ for the potential feasibility of the practical procedure ${ }^{34}$. The IAST selectivity for other compositions (including typical compositions in the air or 


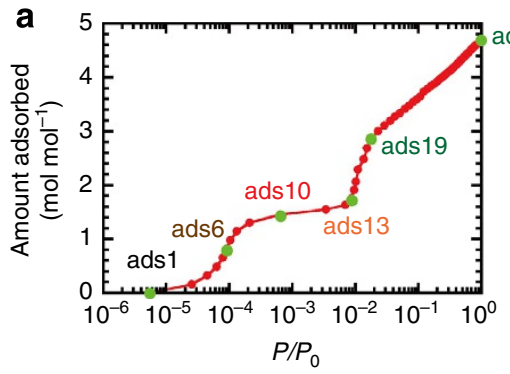

d

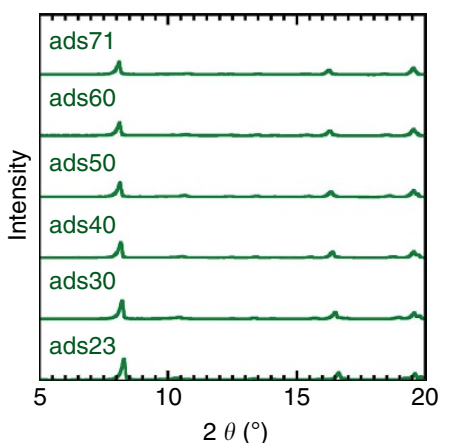

b

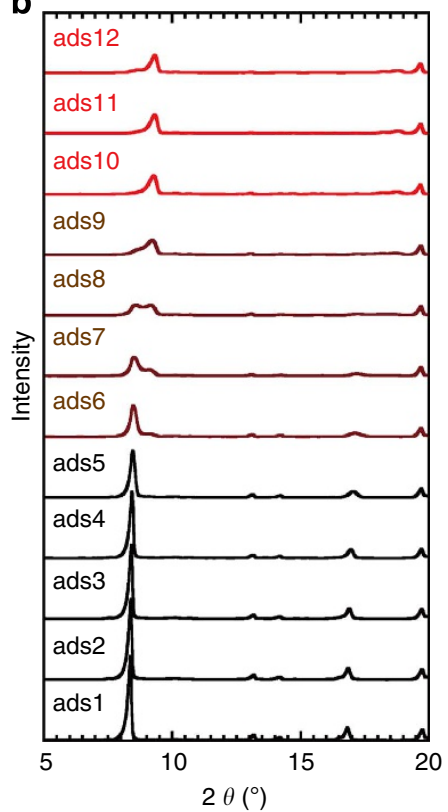

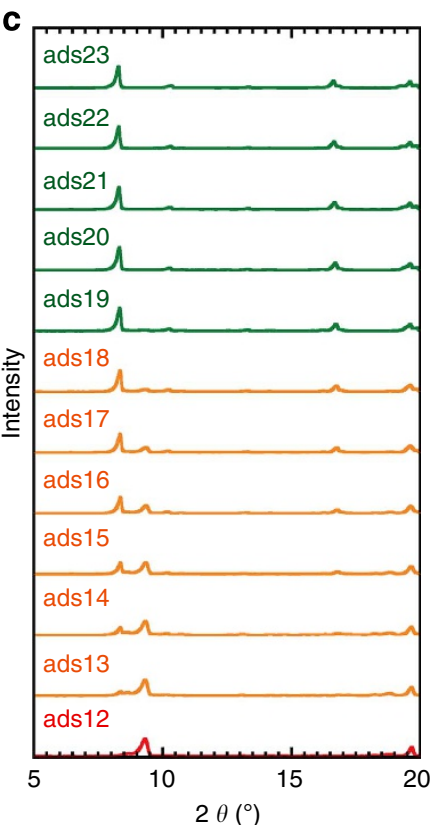

Figure 3 | Coincident X-ray diffraction (XRD)/adsorption measurements of 2. (a) $\mathrm{CO}_{2}$ adsorption isotherm at $195 \mathrm{~K}$. (b-d) XRD patterns measured at each point (ads1-ads23, ads30, ads40, ads50, ads60 and ads71).

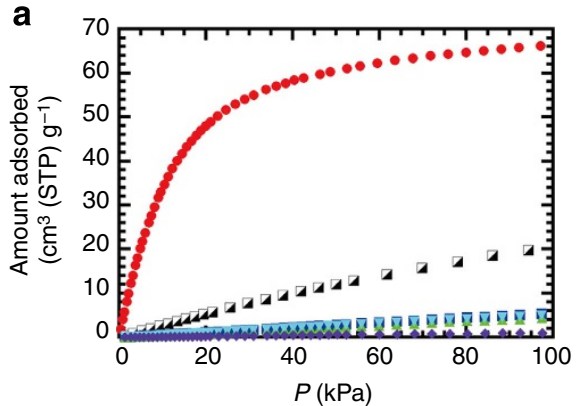

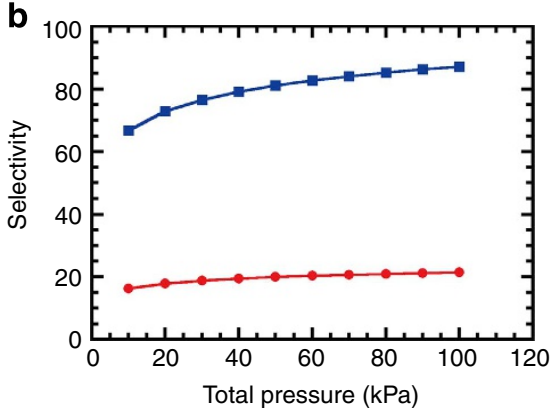
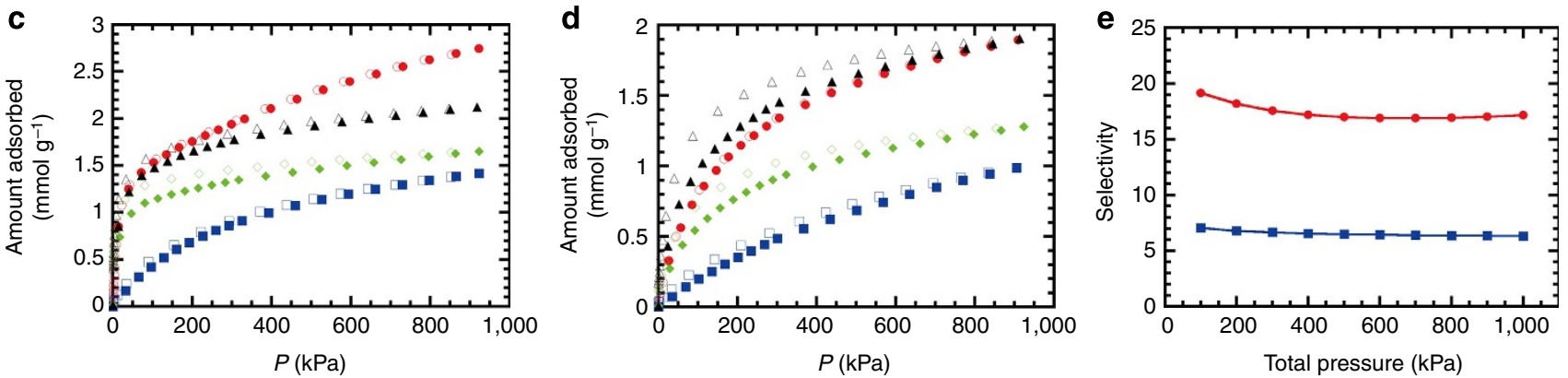

Figure 4 | Gas adsorption properties. (a) Low-pressure adsorption isotherms for $\mathrm{CO}_{2}$ (red circle), $\mathrm{CH}_{4}$ (black half-filled square), $\mathrm{N}_{2}$ (blue square), $\mathrm{O}_{2}$ (green triangle), $\mathrm{Ar}$ (sky-blue inverted triangle) and $\mathrm{H}_{2}$ (purple rhombus) in $\mathbf{2}$ at $298 \mathrm{~K}$. Because the amounts adsorbed for $\mathrm{N}_{2}, \mathrm{O}_{2}$ and $\mathrm{Ar}$ are almost the same, the symbols overlap. (b) Ideal adsorbed solution theory (IAST)-predicted selectivity for $\mathrm{CO}_{2} / \mathrm{CH}_{4}$ (red) and $\mathrm{CO}_{2} / \mathrm{N}_{2}$ (blue) in $\mathbf{2}$ based on the data measured at $298 \mathrm{~K}$ for a bulk gas composition of $\mathrm{CO}_{2}: \mathrm{CH}_{4}=40: 60$ (typical composition of biogas) and $\mathrm{CO}_{2}: \mathrm{N}_{2}=10: 90$ (typical composition of flue gas). (c,d) High-pressure total adsorption/desorption isotherms for $\mathrm{CO}_{2}$ (red circle), $\mathrm{CH}_{4}$ (blue square), $\mathrm{C}_{2} \mathrm{H}_{6}$ (green rhombus), and $\mathrm{C}_{2} \mathrm{H}_{4}$ (black triangle) in $\mathbf{2}$ (c) and $\mathbf{3}$ (d) at $298 \mathrm{~K}$. Adsorption, closed symbols; desorption, open symbols. (e) IAST-predicted selectivity for $\mathrm{CO}_{2} / \mathrm{CH}_{4}$ in $\mathbf{2}$ (red) and $\mathbf{3}$ (blue) based on the data measured at $298 \mathrm{~K}$ for a bulk gas composition of $\mathrm{CO}_{2}: \mathrm{CH}_{4}=40: 60$ (typical composition of biogas).

ternary mixture) is also high (Supplementary Figs 19-24). In addition, high-pressure adsorption measurements were performed at $298 \mathrm{~K}$ (Fig. 4c,d), which confirmed the favourable adsorption of $\mathrm{CO}_{2}$ and $\mathrm{C} 2$ hydrocarbons $\left(\mathrm{C}_{2} \mathrm{H}_{6}\right.$ and $\left.\mathrm{C}_{2} \mathrm{H}_{4}\right)$ relative to $\mathrm{CH}_{4}$ (see Supplementary Figs 25 and 26). The IAST selectivity of $\mathrm{CO}_{2}$ relative to $\mathrm{CH}_{4}$ is still larger than 8 for 2 and slightly smaller than 8 for 3 (Fig. 4e), indicating the practical implementability for biogas purification (vide infra).

Recently, Snurr et al. have used five adsorbent evaluation criteria from the chemical engineering literature for the potential 
use of PCPs/MOFs in $\mathrm{CO}_{2}$ separation processes ${ }^{35}$. We focus on flue gas separation, which is currently an important research area. The typical composition of flue gas, that is, the $\mathrm{CO}_{2} / \mathrm{N}_{2}$ ratio, is assumed to be 10:90 and the adsorption/desorption pressures are set to $100 / 10 \mathrm{kPa}$, respectively. Based on this condition, 2 was evaluated and compared not only with other PCPs/MOFs but also with commercially available inorganic and organic adsorbents (see Supplementary Table 2). As shown in Supplementary Table 2, 2 has high working capacity (or regenerability) and selectivity under these conditions, resulting in a high sorbent selection parameter $(S)$ that combines the working capacity and the adsorption selectivity. The $S$ value obtained (314) is considerably higher than those of zeolites (163 for zeolite 5A and 128 for zeolite $13 \mathrm{X}$ ) and one of the best among the PCPs/ MOFs.

The regenerability of the $\mathrm{CO}_{2}$ adsorption process in $\mathbf{2}$ was measured at $298 \mathrm{~K}$ (Supplementary Fig. 27). Significantly, the $\mathrm{CO}_{2}$ adsorption ability of $\mathbf{2}$ is maintained over repeated cycling, and the material can be regenerated by short vacuum processing without additional heating, in contrast to zeolites, which require high temperatures for complete regeneration (Supplementary Figs 28 and 29). The isosteric heat of $\mathrm{CO}_{2}$ adsorption, $Q_{\mathrm{st}}$, shows values $32-36 \mathrm{~kJ} \mathrm{~mol}^{-1} \quad$ (zero-coverage $Q_{\mathrm{st}}=34.9 \mathrm{~kJ} \mathrm{~mol}^{-1}$, Supplementary Fig. 30), which are smaller than those of aminefunctionalized PCPs and zeolites ${ }^{36,37}$. Such a moderate $Q_{\text {st }}$ value is a strong advantage for the implementation of low-energy regeneration for $\mathrm{CO}_{2}$ separation.

To evaluate the gas separation ability of adsorbents, it is important to study not only the single-gas adsorption properties and IAST simulation under equilibrium conditions, but also mixed gases under flowing (kinetic) conditions. Thus, we conducted a breakthrough experiment, which is a typical way of evaluating the gas separation ability of adsorbents under flowing gas conditions that are related to the pressure swing adsorption (PSA) process. We measured the gas separation properties of 2 and 3 for the $\mathrm{CO}_{2}: \mathrm{CH}_{4}=40: 60$ mixture at $298 \mathrm{~K}$ and under a total pressure of $0.8 \mathrm{MPa}$. The separation of $\mathrm{CO}_{2}$ from $\mathrm{CO}_{2} / \mathrm{CH}_{4}$ mixtures in biogas has become increasingly important in recent times. The PSA process is a well-known technology and the selective binding of the target gas and gas adsorption kinetics are important factors in the design of adsorbent materials. PSA typically runs at ambient temperature and under a total pressure of $0.4-0.8 \mathrm{MPa}$, and the cycle time is several minutes. As shown in Fig. 5, the gas detected first by gas chromatography was $\mathrm{CH}_{4}$ only, with no detection of $\mathrm{CO}_{2}$, indicating high selectivity for $\mathrm{CO}_{2}$ over $\mathrm{CH}_{4}$ under flowing conditions. After a few minutes, the process reached the breakpoint, and then returned to the original gas ratio. It therefore seems that $\mathbf{2}$ and $\mathbf{3}$ have favourable characteristics for $\mathrm{CO}_{2}$ capture, yielding good separation behaviour.

Although high water stability and hydrophobicity are also one of important factors in using gas separation materials under practical conditions, syntheses of PCPs/MOFs showing high $\mathrm{CO}_{2}$ selectivity and no degradation of frameworks under humid environments have been just started ${ }^{38-40}$. Here we tested the stability of frameworks after exposure of $\mathbf{2}$ and $\mathbf{3}$ to water vapour. 2 adsorbs a large amount of $\mathrm{H}_{2} \mathrm{O}$ (Supplementary Fig. 31), and the adsorbed amount of $\mathrm{CO}_{2}$ in 2 after the $\mathrm{H}_{2} \mathrm{O}$ adsorption shows a decrease of $65 \%$ compared with the as-synthesized 2 (Supplementary Fig. 32), suggesting that $\mathbf{2}$ is not stable in humid conditions. On the other hand, a few amount of $\mathrm{H}_{2} \mathrm{O}$ is adsorbed to 3 at $37 \%$ relative humidity, and the adsorbed amount of $\mathrm{CO}_{2}$ is unchanged after the $\mathrm{H}_{2} \mathrm{O}$ adsorption experiment (Supplementary Fig. 33), indicating higher water stability of 3 than 2 . However, it is necessary to further improve the stability to
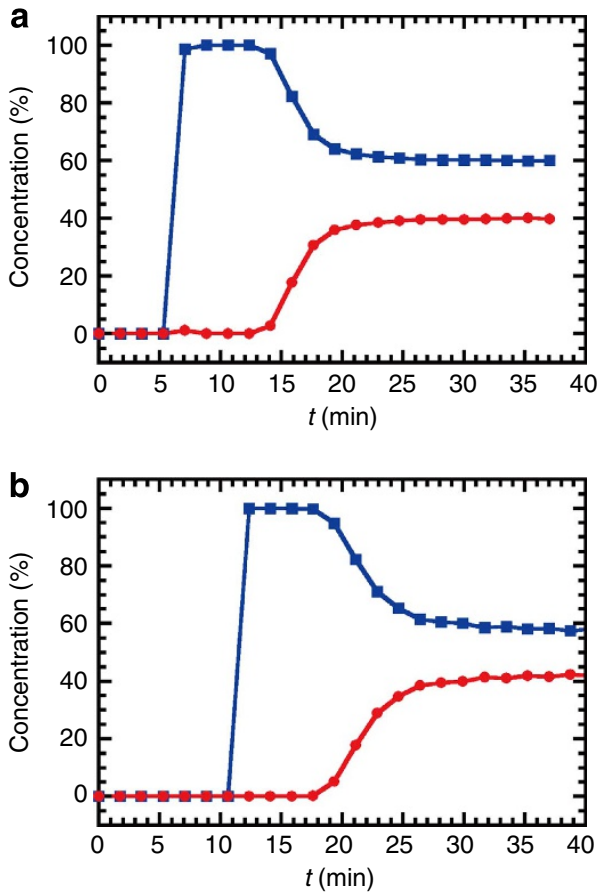

Figure 5 | Gas separation performance. (a,b) Breakthrough curves for a $\mathrm{CO}_{2} / \mathrm{CH}_{4}$ mixture $(40: 60(\mathrm{vol}))$ for $\mathbf{2}(\mathbf{a})$ and $\mathbf{3}(\mathbf{b})$. The red circle is $\mathrm{CO}_{2}$ and the blue square is $\mathrm{CH}_{4}$. These were measured at $298 \mathrm{~K}$, the total pressure was $0.8 \mathrm{MPa}$ and the space velocity was $3 \mathrm{~min}^{-1}$.

water and evaluate gas separation properties under humid conditions.

\section{Discussion}

To our knowledge, almost all PCPs with Group II $\mathrm{Mg}(\mathrm{II})$ and $\mathrm{Ca}$ (II) ions contain only anionic organic ligands; there are few examples including bridging neutral organic ligands. $\mathbf{2}$ and $\mathbf{3}$ are the uncommon examples of Group II $\mathrm{Mg}(\mathrm{II})$ and $\mathrm{Ca}(\mathrm{II})$ PCPs including bridging neutral organic ligands. Note that we can use a variety of neutral organic ligands with pyo moieties, as shown in Supplementary Fig. 34a. In contrast to a monodentate neutral pyridine ligand, even the most simple pyo ligand is capable of bridging metal cations because the coordinated oxygen has two lone-pair electrons. Furthermore, pyo ligands with carboxylate substituents (for example, pyridine-4-carboxylate- $N$ oxide; see Supplementary Fig. 34b) are also useful building blocks for the construction of Group II Mg(II) and Ca(II) PCPs. These considerations strongly suggest that our proposed strategy to use pyo-type ligands will be quite effective for the diversification of Group II $\mathrm{Mg}(\mathrm{II})$ and $\mathrm{Ca}(\mathrm{II})$ PCP frameworks. We can expect the pyo-type ligands to also be good partners to monovalent Group I alkali $\mathrm{Na}(\mathrm{I})$ and $\mathrm{K}(\mathrm{I})$ ions. Although successful studies on syntheses of coordination polymers with Group I alkali metal ions have recently been performed using the neutral cyclodextrin and polyether ligands ${ }^{22,41-43}$, there are still few PCPs containing Group I alkali $\mathrm{Na}(\mathrm{I})$ and $\mathrm{K}(\mathrm{I})$ ions. Their hard acidity impedes the coordination of neutral organic ligands, and the monovalence restricts the number of anionic multicarboxylate ligands (such as $1,4-\mathrm{bdc}^{2}$ and 1,3,5benzenetricarboxylate) coordinating to one Group I alkali $\mathrm{Na}(\mathrm{I})$ and $\mathrm{K}(\mathrm{I})$ ion, which causes difficulty in the formation of porous frameworks. Because of their neutrality and hard basicity, the pyo-type ligands are good candidates to resolve this problem. Therefore, we conclude that the structural diversification of 
PCPs with Group I Na(I) and $\mathrm{K}(\mathrm{I})$ ions and Group II $\mathrm{Mg}(\mathrm{II})$ and $\mathrm{Ca}$ (II) ions that are more abundant on the Earth and more biofriendly than commonly used transition metal ions would be realized by utilizing pyo-type ligands.

In conclusion, we succeeded in finding a new partner, chargepolarized neutral 'bpdo' ligand, for Group II $\mathrm{Mg}$ (II) and $\mathrm{Ca}(\mathrm{II})$ ions in order to realize the structural diversification of $\mathrm{Mg}(\mathrm{II})$ and $\mathrm{Ca}$ (II) PCPs. The bpdo ligand has hard basicity, derived from its polarized structure, which causes the neutral bpdo to bridge hard $\mathrm{Mg}$ (II) and $\mathrm{Ca}(\mathrm{II})$ ions. The obtained $\mathrm{Mg}$ (II) and $\mathrm{Ca}(\mathrm{II}) \mathrm{PCPs}$ with neutral bpdo ligands show sufficient framework stability and good gas separation ability. Our finding opens up the science and engineering of PCPs with cheap and biocompatible Group I and Group II metal ions.

\section{Methods}

Materials. All commercially available starting materials were purchased from Wako Pure Chemical Industries, Ltd., and used as received. The solvents for the syntheses were used without further purification. bpdo was synthesized according to the literature ${ }^{44}$

Synthesis of $\left[\mathrm{Mg}_{\mathbf{2}}(\mathbf{A c O})_{\mathbf{4}}(\mathbf{b p d o})\right]_{\mathbf{n}}$ (1). A DMF solution (5 ml) of $\mathrm{Mg}(\mathrm{A}$ cO $)_{2} \bullet 6 \mathrm{H}_{2} \mathrm{O}(107 \mathrm{mg}, 0.50 \mathrm{mmol})$ and bpdo $(94 \mathrm{mg}, 0.50 \mathrm{mmol})$ was heated at $423 \mathrm{~K}$ for $6 \mathrm{~h}$. The obtained colourless microcrystals were filtered, dispersed in a DMF solution $(20 \mathrm{ml})$ and heated at $373 \mathrm{~K}$ for $10 \mathrm{~min}$. The obtained colourless microcrystals of $\left[\mathrm{Mg}_{2}(\mathrm{AcO})_{4}(\mathrm{bpdo})\right]_{n}$ (1) were filtered, washed with $\mathrm{MeOH}$ and dried at $298 \mathrm{~K}$ under vacuum for $2 \mathrm{~h}$. Yield: $97 \mathrm{mg}, 82 \%$. Elemental analysis: Calcd for 1 $\left(\mathrm{C}_{18} \mathrm{H}_{20} \mathrm{Mg}_{2} \mathrm{~N}_{2} \mathrm{O}_{10}\right): \mathrm{C}=45.71 ; \mathrm{H}=4.26 ; \mathrm{N}=5.92$. Found: $\mathrm{C}=44.10 ; \mathrm{H}=4.32$; $\mathrm{N}=5.44 \%$.

Synthesis of $\left\{\left[\mathbf{M g}_{\mathbf{2}}(\mathbf{1}, \mathbf{4}-\mathrm{bdc})_{\mathbf{2}}\right.\right.$ (bpdo) $] \cdot \mathbf{2 D M F} \boldsymbol{~}_{\boldsymbol{n}}$ (2 $\supset \mathbf{2 D M F )}$. A DMF solution (5 ml) of $\mathrm{MgCl}_{2} \bullet 6 \mathrm{H}_{2} \mathrm{O}(203 \mathrm{mg}, 1.00 \mathrm{mmol}), 1,4-\mathrm{H}_{2} \mathrm{bdc}(166 \mathrm{mg}, 1.0 \mathrm{mmol})$ and bpdo $(94 \mathrm{mg}, 0.50 \mathrm{mmol}$ ) was heated at $423 \mathrm{~K}$ for $24 \mathrm{~h}$. The obtained colourless microcrystals of $\left\{\left[\mathrm{Mg}_{2}(1,4-\mathrm{bdc})_{2}(\mathrm{bpdo})\right] \bullet 2 \mathrm{DMF}\right\}_{n}(2 \supset 2 \mathrm{DMF})$ were filtered, washed with DMF and dried at $298 \mathrm{~K}$ under vacuum for $2 \mathrm{~h}$. Yield: $292 \mathrm{mg}, 41 \%$. Elemental analysis: Calcd for $2 \supset 1.8 \mathrm{DMF} \bullet 0.6 \mathrm{H}_{2} \mathrm{O}\left(\mathrm{C}_{31.4} \mathrm{H}_{29.8} \mathrm{Mg}_{2} \mathrm{~N}_{3.8} \mathrm{O}_{12.4}\right)$ : $\mathrm{C}=53.31 ; \mathrm{H}=4.25 ; \mathrm{N}=7.52$. Found: $\mathrm{C}=52.69 ; \mathrm{H}=4.43 ; \mathrm{N}=7.63 \%$.

Synthesis of $\left\{[\mathbf{C a}(\mathbf{1}, \mathbf{4}-\mathrm{bdc})(\mathrm{bpdo})] \bullet 0.5 \mathrm{DMF} \boldsymbol{\}}_{\boldsymbol{n}}\right.$ (3 $\supset$ 0.5DMF). A DMF solution $(40 \mathrm{ml})$ of $\mathrm{Ca}\left(\mathrm{NO}_{3}\right)_{2} \bullet 4 \mathrm{H}_{2} \mathrm{O}(708 \mathrm{mg}, 3.00 \mathrm{mmol}), 1,4-\mathrm{H}_{2} \mathrm{bdc}(498 \mathrm{mg}, 3.00 \mathrm{mmol})$ and bpdo $(1.13 \mathrm{~g}, 6.00 \mathrm{mmol})$ was heated at $423 \mathrm{~K}$ for $48 \mathrm{~h}$. The obtained colourless microcrystals of $\{[\mathrm{Ca}(1,4-\mathrm{bdc})(\mathrm{bpdo})] \bullet 0.5 \mathrm{DMF}\}_{n}(3 \supset 0.5 \mathrm{DMF})$ were filtered, washed with DMF and dried at $298 \mathrm{~K}$ under vacuum for $2 \mathrm{~h}$. Yield: $1.20 \mathrm{~g}, 97 \%$. Elemental analysis: Calcd for $3 \supset 0.3 \mathrm{DMF}\left(\mathrm{C}_{18.9} \mathrm{H}_{4.1} \mathrm{CaN}_{2.3} \mathrm{O}_{6.3}\right): \mathrm{C}=54.79$; $\mathrm{H}=3.43 ; \mathrm{N}=7.78$. Found: $\mathrm{C}=53.44 ; \mathrm{H}=3.68 ; \mathrm{N}=7.73 \%$.

Physical measurements. Elemental analyses $(\mathrm{C}, \mathrm{H}$ and $\mathrm{N})$ were performed using a Yanaco $\mathrm{CHN}$ corder MT-6. The infrared spectra were recorded using $\mathrm{KBr}$ disks on a Thermo Nicolet 6700 FT-IR spectrometer with a resolution of $4 \mathrm{~cm}^{-1}$. TGDTA analysis was performed using a Rigaku ThermoPlus2/TG-DTA8129 over the temperature range r.t. $-500^{\circ} \mathrm{C}$ under a $\mathrm{N}_{2}$ flow at a heating rate of $10^{\circ} \mathrm{C} \mathrm{min}^{-1}$. Powder XRD data of microcrystals were collected using a Rigaku RINT-Ultima III diffractometer employing $\mathrm{Cu} \mathrm{K} \alpha$ radiation. The adsorption and desorption isotherms for $\mathrm{CO}_{2}(195,288$ and $298 \mathrm{~K}), \mathrm{CH}_{4}(298 \mathrm{~K}), \mathrm{N}_{2}$ (77 and $\left.298 \mathrm{~K}\right), \mathrm{O}_{2}(298 \mathrm{~K})$, $\operatorname{Ar}(298 \mathrm{~K})$ and $\mathrm{H}_{2}(298 \mathrm{~K})$ were recorded on a BELSORP-max volumetric adsorption instrument (BEL Japan, Inc., Supplementary Table 3). The adsorption isotherm measurements for $\mathrm{H}_{2} \mathrm{O}$ at $298 \mathrm{~K}$ were performed using a BELSORP-aqua volumetric adsorption instrument (BEL Japan, Inc.). The high-pressure adsorption and desorption isotherms for $\mathrm{CO}_{2}, \mathrm{CH}_{4}, \mathrm{C}_{2} \mathrm{H}_{4}$ and $\mathrm{C}_{2} \mathrm{H}_{6}(298 \mathrm{~K})$ were measured with a BELSORP-HP volumetric adsorption equipment (BEL Japan, Inc., Supplementary Tables 4 and 5). We estimated the total adsorbed amount using the simple equation $(1)^{45}$ :

$$
N_{\text {total }}=N_{\text {ex }}+\rho_{\text {bulk }} V_{\text {pore }}
$$

where $N_{\text {total }}$ is the total adsorbed amount, $N_{\text {ex }}$ is the surface excess amount, $\rho_{\text {bulk }}$ is the bulk density of the gases and $V_{\text {pore }}$ is the pore volume of the PCPs. Total adsorption was calculated using NIST Thermochemical Properties of Fluid Systems: $\mathrm{CO}_{2}, \mathrm{CH}_{4}, \mathrm{C}_{2} \mathrm{H}_{4}$ and $\mathrm{C}_{2} \mathrm{H}_{6}$ densities between 0 and 2,000 $\mathrm{kPa}$ were fitted using a sixth-order polynomial, then multiplied by the pore volume of each material ${ }^{46}$. The IAST of Prausnitz and Myers was used to estimate the composition of the adsorbed phase from pure component isotherm data ${ }^{33}$. Experimental isotherm data were fitted to the single-site or dual-site Langmuir-Freundlich model (Supplementary Table 6). Selectivities were calculated using the following expression (2):

$$
S=\frac{x_{i} y_{j}}{x_{j} y_{i}}
$$

where $x_{i}$ is the mole fraction of component $i$ in the adsorbed phase and $y_{i}$ is the mole fraction of component $i$ in the bulk. The coverage-dependent isosteric heat of adsorption was evaluated by first fitting the temperature-dependent isotherm data (288 and $298 \mathrm{~K}$, Supplementary Figs 35 and 36) to a virial-type expression ${ }^{47}$, which can be written as follows:

$$
\ln P=\ln N+\frac{1}{T} \sum_{i=0}^{m} a_{i} N^{i}+\sum_{i=0}^{n} b_{i} N^{i}
$$

where $P$ is the pressure, $N$ is the quantity of $\mathrm{CO}_{2}$ adsorbed, $T$ is the temperature, $a_{i}$ and $b_{i}$ are virial coefficients, and $m$ and $n$ are the number of virial coefficients required for adequate fitting of the isotherms. Then, the isosteric heat of adsorption was evaluated using the following expression (4):

$$
Q_{\mathrm{st}}=-R \sum_{i=0}^{m} a_{i} N^{i}
$$

where $R$ is the universal gas constant. The zero-coverage isosteric heat of adsorption is given by:

$$
Q_{\text {st }}=-R a_{0}
$$

Repeated adsorption measurements were performed at $298 \mathrm{~K}$ using the BELSORPmax. The samples after the adsorption measurement were degassed at $298 \mathrm{~K}$ under vacuum for $1 \mathrm{~min}$ and used for the next measurement. Molecular Sieves 13X was used as a reference sample. Coincident infrared/adsorption measurements were carried out at $195 \mathrm{~K}$ using a JASCO model VIR-200 Fourier transform infrared spectrometer connected to a BELSORP-18PLUS volumetric adsorption instrument (BEL Japan, Inc.) with neat samples. Those apparatuses were synchronized with each other and each infrared spectrum was obtained at each equilibrium point of the adsorption/ desorption isotherms. The initial infrared spectrum before $\mathrm{CO}_{2}$ dosage was used as the reference for obtaining the background-subtracted spectra. Coincident XRD/ adsorption measurements were performed at $195 \mathrm{~K}$ using a Rigaku UltimaIV with $\mathrm{Cu}$ $\mathrm{K} \alpha$ radiation connected to a BELSORP-18PLUS. Those apparatuses were synchronized with each other and each powder XRD pattern was obtained at each equilibrium point of the adsorption/desorption isotherms. Breakthrough curve measurements were performed using a hand-made gas flowing system. The sample cell was filled with sample powders, and the temperature of the cell was controlled by a refrigerant circulating system. The gas ratio was $\mathrm{CO}_{2}: \mathrm{CH}_{4}=40: 60$ (vol) and the measurements were executed at $0.80 \mathrm{MPa}$ of total pressure at $298 \mathrm{~K}$ with a space velocity of $3 \mathrm{~min}^{-1}$. The pressure of $\mathrm{CO}_{2}$ was $0.32 \mathrm{MPa}$.

Computational details. Geometry optimizations of organic ligands and a model of 2 were carried out using density functional theory with the B3LYP functional ${ }^{48-51}$. We constructed a finite model based on the X-ray crystal structure of 2 , where four oxygen atoms of bpdo and eight oxygen atoms of bridging carboxylate ligands were replaced by hydroxide ions and water molecules to retain the coordinative environments of $\mathrm{Mg}$, as shown Supplementary Fig. 6. In an optimization process, we fixed the four $\mathrm{Mg}$ atoms to the relative positions observed in the crystal structure, whereas all geometries of organic ligands were optimized. The 6-31G(d, p) basis sets were employed for all atoms, where one set of diffuse functions was added to the $\mathrm{O}$ atoms in carboxylate ligands, bpdo ligands and hydroxide ions. All geometry optimizations, NBO analysis and evaluation of NBO atomic charges were performed using the Gaussian 09 package $^{52}$.

Crystal structure determination. Single-crystal XRD measurements of $\mathbf{1}$, $\mathbf{2} \supset 2 \mathrm{DMF}$ and $\mathbf{3} \supset 0.5 \mathrm{DMF}$ were performed using a Rigaku RAXIS-RAPID imaging plate diffractometer with graphite-monochromated $\mathrm{Mo} \mathrm{K} \alpha$ radiation $(\lambda=0.71075 \AA)$. The data were corrected for Lorentz and polarization effects. The structures were solved using direct methods (SIR2004 (1) and SHELXS-97 $(2 \supset 2 \mathrm{DMF}$ and $3 \supset 0.5 \mathrm{DMF})$ ) and expanded using Fourier techniques ${ }^{53,54}$. All nonhydrogen atoms were refined anisotropically. All hydrogen atoms were refined using the riding model. The refinements were carried out using full-matrix leastsquares techniques on $F^{2}$ using SHELXL-97 ( 1 and $2 \supset$ 2DMF) and SHELXL-2014 $(3 \supset 0.5 \mathrm{DMF})^{54}$ (Supplementary Table 7 and Supplementary Data 1-3). For $3 \supset 0.5 \mathrm{DMF}$, the thermal displacement parameters for one of the disordered bpdo molecules were restrained using the DELU and SIMU commands, and the disordered DMF solvent was refined using the DFIX, DANG, FLAT and EADP commands. For $\mathbf{1}$ and $\mathbf{2} \supset 2 \mathrm{DMF}$, all calculations were performed using the CrystalStructure software package ${ }^{55}$. For $3 \supset 0.5 \mathrm{DMF}$, all calculations were performed using the WinGX software package ${ }^{56}$.

\section{References}

1. Yaghi, O. M. et al. Reticular synthesis and the design of new materials. Nature 423, 705-714 (2003)

2. Kitagawa, S., Kitaura, R. \& Noro, S. Functional porous coordination polymers. Angew. Chem., Int. Ed. 43, 2334-2375 (2004). 
3. Bradshaw, D., Claridge, J. B., Cussen, E. J., Prior, T. J. \& Rosseinsky, M. J. Design, chirality, and flexibility in nanoporous molecule-based materials. Acc. Chem. Res. 38, 273-282 (2005).

4. Férey, G. Hybrid porous solid: past, present, future. Chem. Soc. Rev. 37, 191-214 (2008).

5. Morris, R. E. \& Wheatley, P. S. Gas storage in nanoporous materials. Angew. Chem. Int. Ed. 47, 4966-4981 (2008).

6. Zacher, D., Schmid, R., Wöll, C. \& Fischer, R. A. Surface chemistry of metalorganic frameworks at the liquid-solid interface. Angew. Chem. Int. Ed. 50, 176-199 (2011).

7. Lu, G. et al. Imparting functionality to a metal-organic framework material by controlled nanoparticle encapsulation. Nat. Chem. 4, 310-316 (2012).

8. Cohen, S. M. Postsynthetic Methods for the Functionalization of MetalOrganic Frameworks. Chem. Rev. 112, 970-1000 (2012).

9. Haldar, R. \& Maji, T. K. Metal-organic frameworks (MOFs) based on mixed linker systems: structural diversities towards functional materials. CrystEngComm 15, 9276-9295 (2013).

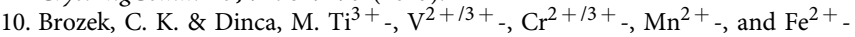
Substituted MOF-5 and Redox Reactivity in Cr- and Fe-MOF-5. J. Am. Chem. Soc. 135, 12886-12891 (2013).

11. Gao, W.-Y. et al. Crystal engineering of an nbo topology metal-organic framework for chemical fixation of $\mathrm{CO}_{2}$ under ambient conditions. Angew. Chem. Int. Ed. 53, 2615-2619 (2014).

12. Takashima, Y., Long, D.-L. \& Cronin, L. Towards imaging electron density inside metal-organic framework structures. Chem. Commun. 50, 2271-2274 (2014).

13. Yamada, T., Otsubo, K., Makiura, R. \& Kitagawa, H. Designer co-ordination polymers: dimensional crossover architectures and proton conduction. Chem. Soc. Rev. 42, 6655-6669 (2013).

14. Makal, T. A., Li, J. R., Lu, W. G. \& Zhou, H. C. Methane storage in advanced porous materials. Chem. Soc. Rev. 41, 7761-7779 (2012).

15. Torad, N. L., Hu, M., Imura, M., Naito, M. \& Yamauchi, Y. Large Cs adsorption capability of nanostructured Prussian Blue particles with high accessible surface areas. J. Mater. Chem. 22, 18261-18267 (2012).

16. Sumida, K. et al. Carbon dioxide capture in metal-organic frameworks. Chem. Rev. 112, 724-781 (2012).

17. Gascon, J. et al. Practical approach to zeolitic membranes and coatings: state of the art, opportunities, barriers, and future perspectives. Chem. Mater. 24, 2829-2844 (2012).

18. Sato, H. et al. Self-accelerating CO Sorption in a soft nanoporous crystal. Science 343, 167-170 (2014).

19. Lee, J. et al. Metal-organic framework materials as catalysts. Chem. Soc. Rev. 38, 1450-1459 (2009).

20. Meng, L. et al. Crystal engineering of a microporous, catalytically active fcu topology MOF using a custom-designed metalloporphyrin linker. Angew. Chem. Int. Ed. 51, 10082-10085 (2012).

21. Gu, X., Lu, Z.-H., Jiang, H.-L., Akita, T. \& Xu, Q. Synergistic catalysis of metal-organic framework-immobilized $\mathrm{Au}-\mathrm{Pd}$ nanoparticles in dehydrogenation of formic acid for chemical hydrogen storage. J. Am. Chem. Soc. 133, 11822-11825 (2011).

22. Fromm, K. M. Coordination polymer networks with s-block metal ions. Coord. Chem. Rev. 252, 856-885 (2008).

23. Miller, S. R. et al. A rare example of a porous Ca-MOF for the controlled release of biologically active NO. Chem. Commun. 49, 7773-7775 (2013).

24. McDonald, T. M. et al. Capture of carbon dioxide from air and flue gas in the alkylamine-appended metal-organic framework mmen- $\mathrm{Mg}_{2}$ (dobpdc). J. Am. Chem. Soc. 134, 7056-7065 (2012).

25. Caskey, S. R., Wong-Foy, A. G. \& Matzger, A. J. Dramatic Tuning of carbon dioxide uptake via metal substitution in a coordination polymer with cylindrical pores. J. Am. Chem. Soc. 130, 10870-10871 (2008).

26. Senkovska, I. \& Kaskel, S. Solvent-Induced pore-size adjustment in the metalorganic framework $\left[\mathrm{Mg}_{3}(\mathrm{ndc})_{3}(\mathrm{dmf})_{4}\right]$ (ndc = naphthalenedicarboxylate). Eur. J. Inorg. Chem. 2006, 4564-4569 (2006).

27. Dincă, M. \& Long, J. R. Strong $\mathrm{H}_{2}$ binding and selective gas adsorption within the microporous coordination solid $\mathrm{Mg}_{3}\left(\mathrm{O}_{2} \mathrm{C}-\mathrm{C}_{10} \mathrm{H}_{6}-\mathrm{CO}_{2}\right)_{3}$. J. Am. Chem. Soc. 127, 9376-9377 (2005).

28. Banerjee, D., Zhang, Z., Plonka, A. M., Li, J. \& Parise, J. B. A calcium coordination framework having permanent porosity and high $\mathrm{CO}_{2} / \mathrm{N}_{2}$ selectivity. Cryst. Growth Des. 12, 2162-2165 (2012).

29. Mallick, A. et al. Fine-tuning the balance between crystallization and gelation and enhancement of $\mathrm{CO}_{2}$ uptake on functionalized calcium based MOFs and metallogels. J. Mater. Chem. 22, 14951-14963 (2012).

30. Spek, A. L. Structure validation in chemical crystallography. Acta Crystallogr., Sect. D 65, 148-155 (2009).

31. Shannon, R. D. Revised effective ionic radii and systematic studies of interatomic distances in halides and chalcogenides. Acta Crystallogr. Sect. A 32, 751-767 (1976)

32. Serre, C. et al. An explanation for the very large breathing effect of a metalorganic framework during $\mathrm{CO}_{2}$ adsorption. Adv. Mater. 19, 2246-2251 (2007).
33. Myers, A. L. \& Prausnitz, J. M. Thermodynamics of mixed-gas adsorption. AIChE. J. 11, 121-127 (1965).

34. Hamon, L., Jolimaître, E. \& Pirngruber, G. D. $\mathrm{CO}_{2}$ and $\mathrm{CH}_{4}$ separation by adsorption using Cu-BTC metal-organic framework. Ind. Eng. Chem. Res. 49, 7497-7503 (2010).

35. Bae, Y.-S. \& Snurr, R. Q. Development and evaluation of porous materials for carbon dioxide separation and capture. Angew. Chem. Int. Ed. 50, 11586-11596 (2011).

36. McDonald, T. M., D’Alessandro, D. M., Krishna, R. \& Long, J. R. Enhanced carbon dioxide capture upon incorporation of $N, N^{\prime}$-dimethylethylenediamine in the metal-organic framework CuBTTri. Chem. Sci 2, 2022-2028 (2011).

37. Dunne, J. A., Rao, M., Sircar, S., Gorte, R. J. \& Myers, A. L. Calorimetric heats of adsorption and adsorption isotherms. 2. $\mathrm{O}_{2}, \mathrm{~N}_{2}, \mathrm{Ar}, \mathrm{CO}_{2}, \mathrm{CH}_{4}, \mathrm{C}_{2} \mathrm{H}_{6}$, and $\mathrm{SF}_{6}$ on NaX, H-ZSM-5, and Na-ZSM-5 zeolites. Langmuir 12, 5896-5904 (1996).

38. Nugent, P. et al. Porous materials with optimal adsorption thermodynamics and kinetics for $\mathrm{CO}_{2}$ separation. Nature 495, 80-84 (2013).

39. Fracaroli, A. M. et al. Metal-organic frameworks with precisely designed interior for carbon dioxide capture in the presence of water. J. Am. Chem. Soc. 136, 8863-8866 (2014).

40. Shekhah, O. et al. Made-to-order metal-organic frameworks for trace carbon dioxide removal and air capture. Nat. Commun. 5, 4228 (2014).

41. Smaldone, R. A. et al. Metal-organic frameworks from edible natural products Anegw. Chem. Int. Ed. 49, 8630-8634 (2010).

42. Gassensmith, J. J. et al. Strong and reversible binding of carbon dioxide in a green metal-organic framework. J. Am. Chem. Soc. 133, 15312-15315 (2011).

43. Forgan, R. S. et al. Nanoporous carbohydrate metal-organic frameworks. J. Am. Chem. Soc. 134, 406-417 (2012).

44. Chamayou, A.-C. \& Janiak, C. A $>22 \AA$ long metal-complex anon and a 1D cationic coordination polymer, both based on $4,4^{\prime}$-bipyridine- $N, N^{\prime}$-dioxide, yielding a $3 \mathrm{D}$ and 2-fold interpenetrated fsc net of the hydrogen-bonded metalorganic 1D polymer. Inorg. Chim. Acta 363, 2193-2200 (2010).

45. Neimark, A. V. \& Ravikovitch, P. I. Calibration of pore volume in adsorption experiments and theoretical models. Langmuir 13, 5148-5160 (1997).

46. Lemmon, E. W., McLinden, E. W. \& Friend, D. G. in NIST Chemistry WebBook, NIST Standard Reference Database Number 69 (eds Linstrom, P. J. \& Mallard, W. G.) 20899 (National Institute of Standards and Technology, 2003).

47. Czepirski, L. \& Jagiello, J. Virial-type thermal equation of gas-solid adsorption. Chem. Eng. Sci. 44, 797-801 (1989).

48. Becke, A. D. Density-functional thermochemistry. III. The role of exact exchange. J. Chem. Phys. 98, 5648-5652 (1993).

49. Lee, C., Yang, W. \& Parr, R. G. Development of the Colle-Salvetti correlationenergy formula into a functional of the electron density. Phys. Rev. B 37, 785-789 (1988).

50. Becke, A. D. Density-functional exchange-energy approximation with correct asymptotic behavior. Phys. Rev. A 38, 3098-3100 (1988).

51. Miehlich, B., Savin, A., Stoll, H. \& Preuss, H. Results obtained with the correlation energy density functionals of becke and Lee, Yang and Parr. Chem. Phys. Lett. 157, 200-206 (1989).

52. Frisch, M. J. et al. Gaussian 09, Revision D.01 (Gaussian, Inc., 2009).

53. Burla, M. C. et al. SIR2004: an improved tool for crystal structure determination and refinement. J. Appl. Crystallogr 38, 381-388 (2005).

54. Sheldrick, G. M. A short history of SHELX. Acta Crystallogr. Sect. A 64, 112-122 (2008).

55. CrystalStructure 4.0.1: Crystal Structure Analysis Package; Rigaku Corp.: Tokyo, Japan (2000-2010).

56. Farrugia, L. J. Win GX suite for small-molecule single-crystal crystallography. J. Appl. Crystallogr. 32, 837-838 (1999).

\section{Acknowledgements}

This work was supported by PRESTO-JST and a Grant-in-Aid for Scientific Research (No. 24550068) from the Ministry of Education, Culture, Sports, Science and Technology, Japan, and the Shitagau Noguchi Foundation.

\section{Author contributions}

S.-i.N. designed this study, interpreted the results and wrote the paper. S.-i.N. and J.M performed the experiments. Y.H. carried out the calculations. R.M., H.S. and S.K. performed the coincident infrared/adsorption and XRD/adsorption measurements. K.S. carried out the structural analysis. Y.I. performed the high-pressure adsorption and breakthrough curve measurements. All authors discussed the results and commented on the manuscript.

\section{Additional information}

Accession codes: The X-ray crystallographic coordinates for structures reported in this Article have been deposited at the Cambridge Crystallographic Data Centre (CCDC), 
under deposition numbers 997086 to 997088 . These data can be obtained free of charge from the Cambridge Crystallographic Data Centre via www.ccdc.cam.ac.uk/data_request/cif.

Supplementary Information accompanies this paper at http://www.nature.com/ naturecommunications

Competing financial interests: The authors declare no competing financial interests.

Reprints and permission information is available online at http://npg.nature.com/ reprintsandpermissions/
How to cite this article: Noro, S.-i. et al. Porous coordination polymers with ubiquitous and biocompatible metals and a neutral bridging ligand. Nat. Commun. 6:5851 doi: 10.1038/ncomms6851 (2015).

(c) (i) This work is licensed under a Creative Commons Attribution 3.0 Unported License. The images or other third party material in this article are included in the article's Creative Commons license, unless indicated otherwise in the credit line; if the material is not included under the Creative Commons license, users will need to obtain permission from the license holder to reproduce the material. To view a copy of this license, visit http://creativecommons.org/licenses/by/3.0/ 